\title{
Penile Ectopic Testis (PET) Case Report in Adulthood in Rural Area of Africa: An Uncommon Cause of Dyspareunia
}

\author{
Amouzou Efoe-Ga, (MD, Surgeon, specialist registrar) \\ Sogan Ananivi, (MD, Surgeon) \\ University of Lomé, Togo \\ Sikpa Komi, (MD, Urologist, specialist registrar) \\ University of Kara, Togo \\ Sambiani Damigou, (MD, Surgeon) \\ Dosseh Ekoue, (MD, Surgeon, Professor) \\ University of Lomé, Togo
}

Doi: 10.19044/esj.2018.v14n21p132 URL:http://dx.doi.org/10.19044/esj.2018.v14n21p132

\begin{abstract}
Penile ectopic testis is a rare congenital abnormality with an etiopathogenesis poorly understood nowadays. We report a case of a 19 years old boy admitted for left groin hernia with dyspareunia whose management in rural area consisted in an orchidopexy in dartos completed by a normal sperm count and a normal testicular biopsy.
\end{abstract}

Keywords: Penile ectopic testis, adulthood, Africa.

\section{Introduction}

Ectopic testes are most commonly found in the superficial inguinal pouch of Dennis Browne. Other, less common, locations include the contralateral scrotum, base of penis, ipsilateral thigh, and perineum (Pugach, 2002). Penile ectopic testis (PET) was first recorded in France by Popow in 1888 (Popow, 1988). Poupart in 1897 included the penile location in his review of testicular ectopia (Poupart, 1897). This is an uncommon variety of ectopic testes presenting the same complications risk as every testicular migration abnormality (Diabate, 2011). The diagnosis is often easy but can sometime be difficult especially in rural areas where there is a lack of specialist and lateness in consultation. We report the case of a young man sexually active presenting a PET with dyspareunia managed surgically. 


\section{Case Report}

We present a 19 years old schoolboy who was referred in the Hospital 'Saint jean de Dieu' in Togo (western Africa) in June 2016. The case was presented as left inguinal hernia with dyspareunia. The examination in our center has rather found a left PET without any associated groin hernia. The physical examination had shown masculine external genital organs with signs of puberty; and an oval swelling on the dorsal side of the penile shaft (Figure 1). This mass was non-tender and had a smooth surface. The left hemiscrotum was underdeveloped and empty. He had a normally descended right testis (figure 2). He had a well-developed and circumcised penis too. The surgical exploration found an hypotrophic epididymo-testicular kit without any gubernaculum testis but with an adhesion between albuginea and tunica vaginalis. A thorough dissection in order to dissociate testicle from it covering tissues was performed (figure 3) and completed by orchidopexy in dartos and testicle biopsy with pathological examination. Immediate post-operative outcome was good with a normal sperm count and no sign of malignancy on the biopsy lab test. A two years follow-up assessment showed no recurrence or abnormal findings.

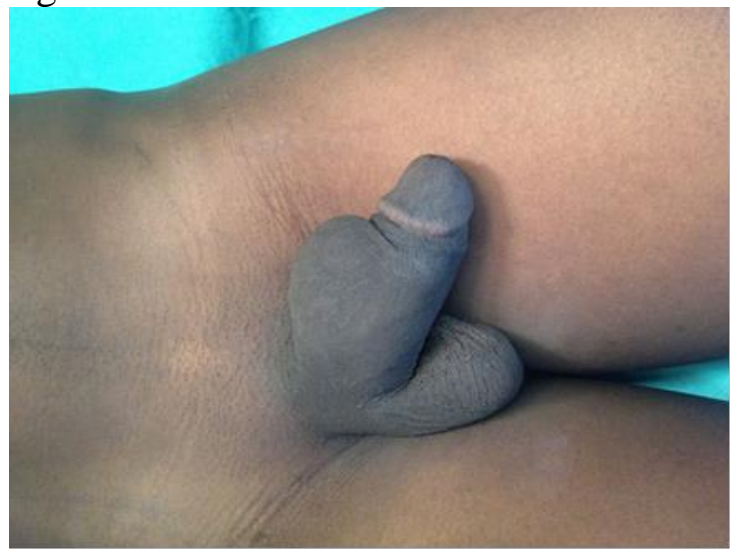

Figure 1. (anterior view of penis)

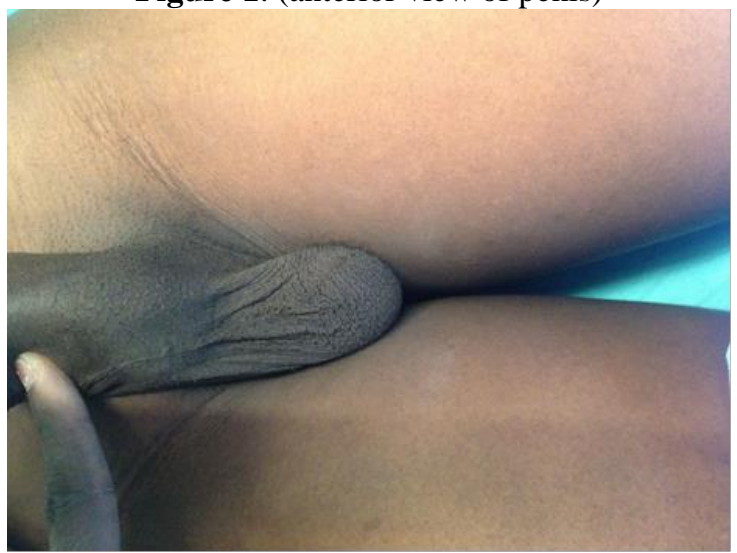

Figure 2. (anterior view of scrotum) 


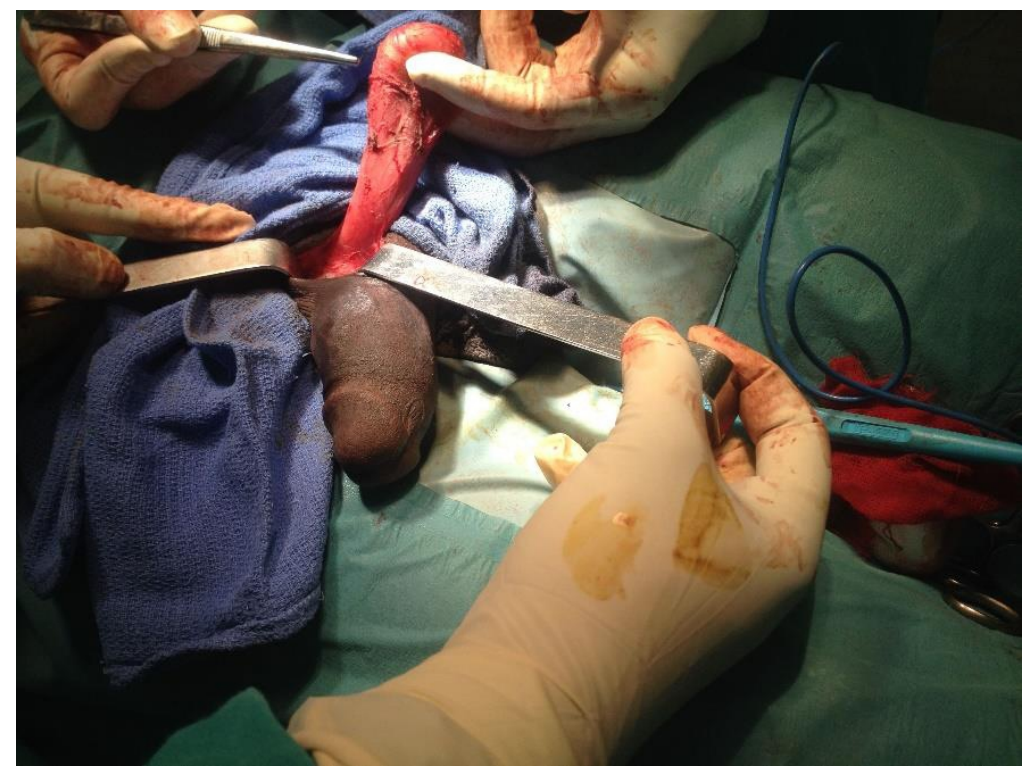

Figure 3. (dissection of the spermatic cord)

\section{Comment}

The PET is an extremely rare disease (Pugach, 2002) and represent with all other testicular ectopia less than $1 \%$ of all testicular migration disorders (Merrot, 2009). PET is a rare genital malformation associated with a change in the implementation of the gubernaculum after the passage in the inguinal canal (Mota, 2012). Many factors may speculate the etiopathogenesis of PET that can be considered as testicle migration abnormalities. In PET and more likely in ectopic testes, there are two mechanisms and the main one is mechanical one due to gubernaculum testis abnormalities and it nerve (genitofemoral nerve) (Jlidi, 2004). We described a case of a PET localized under the skin on the dorsal aspect of the penis. other localizations have been reported in the literature on lateral sides of the penis with or without crossing the median line (Pugach, 2002). Many cases described in literature concerned children; and in Africa we can quote Diabate and Appiah respectively in Senegal and Ghana) (Diabate, 2011; Mota, 2012; Jlidi, 2004; Appiah, 2015).

However, Concorda and Hedge have also reported PET cases in adolescents similar to the case we presented above in the U.S and India respectively; but we did not find any case of PET reported in adolescents in Africa (Concorda, 1976; Hedge, 1987). PET must be surgically managed as soon as possible in the first year of life in order to avoid complications like spermatogenesis dysregulation, trauma, torsion or cancerization. For that purpose, our decline was not enough to evaluate the long-term follow up of this abnormality which presents rather significant risk factors such as the evolution over the last 19 years and poverty context (Diabate, 2011). 


\section{Conclusion}

Penile ectopic testis in adulthood are rare but their diagnosis that is based on clinical examination can simulate a groin hernia. Thus, a thorough and methodical examination remains the key to a good diagnosis. The followup must be at long term in order to manage an eventual complication even treated.

\section{Patient Perspective}

The patient answered our call and consulted with satisfaction in relation to the disappearance of symptoms after two years follow up (June 2018).

\section{Informed consent}

The patient gave informed consent (in french) during the first follow up consultation on September 2016.

\section{References:}

1. Appiah, A. A., Azorliade, R., Amoah, G., \& Gyasi-Sarpong, C. K. (2015). Penile Ectopic Testis: An Uncommon Cause of an Empty Scrotum. British Journal of Medicine and Medical Research, 5(7), $962-$ 965.

2. Concodora, J. A., Evans, R. A., \& Smith, M. J. V. (1976). Ectopic penile testis. Urology, 8(3), 263-264.

3. Diabaté, I., Bray, K., \& Sow, I. (2011). L'ectopie testiculaire pénienne : à propos d'un cas. Basic and Clinical Andrology, 21(3), 199.

4. Hegde, D. K., Lal, S. S., Shilotri, P. P., \& Patkar, A. N. (1987). Penile ectopic testis. Indian Journal of Urology, 3(2), 85.

5. Jlidi, S., Echaieb, A., Ghorbel, S., Khemakhem, R., Ben Khalifa, S., \& Chaouachi, B. (2004). L'ectopie testiculaire périnéale. A propos de quatre observations pédiatriques. Progrès en Urologie, 14(4), 532.

6. Merrot, T. (2009). Prise en charge des testicules non descendus. Progrès en urologie, 19(4), 265-268.

7. Mota, R. L., Lopes, F. A., Rodrigues, T., \& Rolim, N. (2013). Penile testis ectopia: a rare urogenital condition. BMJ case reports, 2013.

8. Popow, W. (1888). Ectopic testiculare peno-pubienne anterioure. Bull. Soc. Anat., 63, 655-657.

9. Poupart, J. A. É. J. (1897). Un type nouveau d'ectopie testiculaire (Doctoral dissertation).

10. Pugach, J. \& Steinhardt G. (2002). Evaluation and management of ectopic penile testis. Urology, 59(1), 137. 